\title{
Repeat Focus Group Discussions as a Tool for Strengthening of Management Capacity in a Community Development Project in Western China
}

\author{
Anethe Ljunggren, Zuli Huang, Eva Johansson \\ Karolinska Institutet, Department of Public Health Sciences, Division of Global Health, Stockholm, Sweden \\ Email: anethe lj@hotmail.com
}

Received 9 October 2014; revised 1 November 2014; accepted 8 November 2014

Copyright (C) 2014 by authors and Scientific Research Publishing Inc.

This work is licensed under the Creative Commons Attribution International License (CC BY). http://creativecommons.org/licenses/by/4.0/

c. (i) Open Access

\section{Abstract}

This qualitative study was conducted in a community development structured project, in Ganzi Autonomous Prefecture, Sichuan, China. The paper is the third in a series of three based on the same community intervention. This paper focuses on management capacity building during the intervention. Our interest was to understand how decisions were made in a management team; how they interpreted their own roles; how they interacted and became involved and more spontaneous; and how they pursued new ideas. Three components were combined in order to build capacity, to use repeat FGDs for data collection, monitoring and empowerment, to organize training for the managers and to conduct core group meetings once a year. Content analysis was chosen as the method for examination of the material. Some key issues emerged out of this study. Firstly, the managers from different levels agreed that it helped generate communication, friendship, transparency, trust and improved skills. A second issue, during the process of implementation, was that the managers described change towards empowerment. Ultimately, for the stakeholders the repeat FGDs became a practical way for regular monitoring. The combination of repeat FGDs, training and core group meetings was successful. We understood from the participants that: training had given them improved knowledge; core group meetings had truly made them part of decision making and the repeat FGDs had equipped them with awareness of their own potentials and capacity.

\section{Keywords}

Community Development, Managers' Capacity Building, Empowerment, Participation, Repeat Focus Group Discussions, China, Training, Core Group Meetings 


\section{Introduction}

To be successful in a long term, perspective encompasses mechanistically presented not only competence required within organizations, but also the more difficult areas of social responsibility, high standards of moral and ethical behaviours [1]. There is a need to prepare community leaders and managers to early assume project leadership in order to transfer ownership for best community participation [2]. The community's necessary, involvement in identification of project process indicators, on sustainability, implies sharing of power, skills, knowledge, and experiences that empowers them, together with other stakeholders, feed into decision making fora [3]. The ability of people to act together on social, economic, political and environmental issues helps them to build social capital, which Putnam (1993) [4] describes as "glue" in the community. Implemented through responsive key institutions to the needs of local communities and volunteer activists (e.g. the Red Cross) together with different stakeholders at all levels, the building of social capital could be sustained [5] [6].

This paper focuses on the management capacity during the implementation process of a community development project in China. The study started in 2001, targeting managers in Ganzi Tibetan Autonomous Prefecture, Sichuan Province in Western China with focus on the development process, the participative approach and the involved people's empowerment [7]-[9]. It is the third in a series of three papers, based on the same community development intervention. The first paper is about promoting community empowerment using a model of repeat Focus Group Discussions (FGDs), training and practice in the community [10] and the second paper using the same model of repeat FGDs centre attention on endurance of aloneness among Tibetan indigenous women [11].

The specific geographical reality in the vast Ganzi prefecture combined with low population density influenced by poverty, multicultural setting and language barriers, is challenging for community development initiatives. Modernizations have resulted in conditions of co-existing multiple systems of authority, dominant and subdominant ideologies and a myriad of institutional and non-institutional structures [12].

The project idea was to introduce a concept, which implies a more participatory and local empowering approach that was typical in past efforts of China [13]. We wanted to avoid shortcomings reported by others and try to support and strengthen grassroots capacity to improve control over the conditions that affected their lives, through the participation of a local non-governmental organization (NGO), the Chinese Red Cross, with the support of the Norwegian Red Cross. The Chinese Red Cross already had an administrative and operational structure from national to branch levels in the province, prefecture and county. The need for high-quality functioning and coordinated management and leadership was a priority.

Few grassroots' organizations have developed a culture of accountability and fears that managers will be held responsible for outcomes that are influenced by environmental contexts beyond their control [14]. Funders' desire for measurable outcomes may consequently cause the most vulnerable or hardest-to-reach populations to be ignored in favor of easy targets. The Ganzi project ambition was to support people difficult-to-reach. This intervention arrived at participation and ownership in using repeat FGDs.

We wanted to study how decisions were made in a management team; how they interpreted their own roles; how they interacted and became involved and more spontaneous, and how they pursued new ideas.

\section{Methodology}

\subsection{Setting}

This present study was conducted in a community development project in Ganzi, where almost half of the population is classified as poor, while in China as a whole, approximately $17 \%$ of the population lives below the income poverty line of one USD/day [15]. Poverty, isolation, language barriers and high altitudes create challenges for health and daily life. For the Tibetans, who live in the rural hinterlands, medical facilities are scarce and health workers have a limited medical training [16]. The study area comprises of 153,000 square $\mathrm{km}$ with a population of 877,200 , of which $78 \%$ are Tibetans, predominantly consisting of Tibetan Buddhists. Religious influence has permeated culture, art, social customs and daily life [17] [18].

\subsection{The Intervention}

The intervention was carried out in four out of 18 counties in Ganzi Prefecture. A local (NGO) and the local government were involved in the selection of counties. The structure of the NGO (the Red Cross) and the government follow almost, the same administrative system and routines at four levels; national, provincial, prefec- 
tural and county.

A core group was formed including all managers from national, provincial, prefectural and county levels. Over all project planning was done in the core group, where also representatives of the supporting NGO were part. Operational decisions were taken at all levels. In order to achieve and maintain a high level of competence we focused on how management capacity could be supported, strengthened and developed [1]. Our interest was not only the mechanistic formulaic competences but also the social responsibility, standard of moral and ethical behaviour. Early in the process, we gave the intervention a work name "The Ganzi model" in which our interest was to involve managers from all the different levels. The importance was to let the managers meet, and be informed and trained on the model structure together for a common understanding [19].

Three components were combined in order to build capacity. One component was to use repeat focus group discussions (FGDs) for data collection, monitoring and empowerment [10] [11]. The second component was to organize training for the managers during three one-week periods followed by yearly refreshment courses. The local managers were during the training given particular tasks to accomplish in their own communities to be presented in the following training session. The third component was to organize core group meetings once a year.

Included in the curriculum for the managers' training were NGO policy, project design and strategy, budgeting, monitoring, evaluation, and reporting. Topics like leadership, human recourse issues, project coordination, fundraising and working with donors were emphasized. Assessments, FGD technique, social responsibility and communication were other themes included. Relevant health and social issues such as HIV/Aids, gender sensitisation, human rights and poverty reduction were also included after evaluation and upon request.

\subsection{Participants}

The project area was visited 16 times during the five years of intervention.

Fifty managers, already representing the NGO and the local government were selected for training. Nineteen out of the 50 managers were purposively selected for participation in focus group discussions, core group and further training and directly involved in the study. A total of five Focus Group Discussions (FGDs) were conducted [20] with the managers. The majority of the participants were of Han Chinese origin and a few of Tibetan origin. One fourth of the participants were women.

Out of the 19 initially selected managers a few participated in all the components of the project (training, FGDs, core group) during the entire project period. Twelve out of the 19 participated during three years and a small group only sporadically (participants from national level).

Training was from the beginning conducted at county and prefecture levels and later at provincial level. Three managers from the provincial level were exchanged after three years because of reorganization. Two managers from the prefecture level participated from the beginning in all the components. After the completion of this study, they became facilitators and monitored the continuation of the intervention. We found it important to involve managers from as many levels of the system as possible in order to anchor the intervention and thereby achieve ownership and sustainability.

The research team was composed of one Chinese assistant investigator (female MTCM) and two Swedish investigators (specialists in Public Health). Both Swedish researchers have vast experience of international health and work in low and middle-income countries.

\subsection{Data Collection and Analysis}

Focus group discussions are group discussions exploring a specific set of issues [20]-[22]. Focus group discussions are distinguished from the broader category of group interviews by the explicit use of group interaction/dynamics to generate data. Instead of asking questions of each participant in turn, they are encouraged to talk to one another, asking questions, exchanging anecdotes, and comment on each others' experiences and points of view; thus the participants create an audience for one another. We define in this paper repeat focus group discussion as a method or process, where FGDs are repeatedly performed with preferably more or less the same group of participants [11] [10].

We assumed, that repeat FGDs would be an optimal instrument for monitoring of the intervention in this specific context, with managers representing different levels of the organization, to secure communication channels in both directions and to build trust between the researchers and the focus group participants. The specific dy- 
namics, which are created during FGDs, were also assumed to contribute to an increasingly lively discussion. Kunene (2000) [23] found that advantages of repeat sessions included greater report as well as greater truthfulness in the groups and over time. A further advantage of repeat sessions was the longitudinally qualitative data collection.

The basis for the use of repeat FGDs, combined with training, community practice and core group meetings, as an interventional tool, was to create team spirit and responsibility, to share information and reflect on significant situations and in managing the NGO. It was also to establish networks, feelings of ownership and participation in the intervention from a micro perspective by strengthening social interaction and trust among individuals in the managers' team. Putnam (1993) [4] defines social capital in a community as a community with high levels of engagement, social interaction, trust, and social structures, which serve to enhance cooperation between its' citizens. Social capital consequently consists of all networks, norms, structures and institutions, which facilitate social interaction. We believe, that the development of social capital in the managing team could be a strength for the implementation process that could support development of the NGO's structure and the improvement of community health.

Focus group discussions were conducted yearly five times. The repeat FGDs were in the beginning conducted by a facilitator/moderator (principle investigator) with the support from an interpreter (assistant investigator). With time, the assistant investigator took over more and more as moderator.

An emergent design implies that finding in one FGD can be used to adjust the line of questioning/discussion in the next FGD. This process leads to the participants to a lager extent guide the development of the FGD according to their own desires and needs. This means that the process is partly owned and controlled by the participants and that the initial line of questioning/discussions change over time [24]. The FGDs were tape-recorded and lasted for approximately 90 minutes per session. The FGDs were orally translated into English during the sessions and transcribed in Chinese after each discussion and later translated and transcribed into English. To avoid misunderstandings caused by multiple-language translations, the results were brought back to the focus group for comments. Main issues discussed in the FGDs were: the repeat FGDs, the training, the core group meetings, and the interventional method. We introduced the themes in an unstructured way to facilitate for the participants to freely form associations about factual concerns that could broaden their perspectives.

The core group meetings had three objectives, one was for decision making, secondly was for formative evaluation [25] of the development process and thirdly to strengthen transparency, democratic thinking and teamwork.

Content analysis [26] was chosen as the method for examination of the material.

Permission to carry out the study was obtained from the district authorities in China and clearance was obtained from the Karolinska Institute, Stockholm, Sweden. Verbal consent was obtained from the participants prior to the data collection.

\section{Findings}

The first FGD turned out to be more like an ordinary meeting than a dynamic focus group discussion. Later the participants in the repeat FGDs became more relaxed, improved trustfulness, talked without difficulty, openly and longer. They also showed less prestige, listened more to each other and showed joy in participating in the FGDs. In the beginning the participants tended to come back to economic problems and funding. For every new repeat FGD the participants talked more and more about ability, capacity, improvement and sustainability.

In the coding process the underlying theme, empowerment of managers through a participatory approach process evolved, and three sub-themes a) building of capacity b) building up democratic thinking through networking and c) influencing empowerment through broad and long participation, were identified (Table 1). The findings are based on the perceptions and experiences conveyed by the participants in the repeat FGDs and are illustrated with quotations from the participants.

\subsection{Empowerment of Managers through a Participatory Approach}

The participants in the FGs discussed how the participatory approach was totally new to them and how it had influenced their personal capacity. Those, who had participated during a long time in the intervention stated, that they had become more social, developed better self-confidence, expressed ideas more explicitly and had grown to be less reluctant to innovations and change. 
Table 1. Example of the coding process manifest and latent content analysis.

\begin{tabular}{|c|c|c|c|c|}
\hline \multirow{2}{*}{ 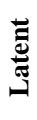 } & \multirow{2}{*}{$\begin{array}{l}\text { Main theme } \\
\text { Sub themes }\end{array}$} & \multicolumn{3}{|c|}{ Empowering managers through a participatory approach } \\
\hline & & Building of capacity & $\begin{array}{l}\text { Build up democratic thinking } \\
\text { through networking }\end{array}$ & $\begin{array}{l}\text { Influencing empowerment through } \\
\text { broad and long participation }\end{array}$ \\
\hline \multirow{4}{*}{ 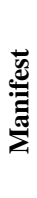 } & Category & Improved competence & Foundation of democratic behaviour & Change of attitudes and knowledge \\
\hline & & Ability & Communication friendship & Changing willingness to listening \\
\hline & Codes & Knowledge & Transparency & Changing sharing of experiences \\
\hline & & Understanding & Team spirit & \\
\hline
\end{tabular}

"I have improved my personal ability a lot...before I became easily nervous when I talked in front of other people...now, I express my ideas without fear...I have a better social control and I am less reluctant.” Repeat FGD, 4

Participants, who had become involved at a later stage in the intervention and had participated in fewer FGDs and core group meetings, but attended all training modules, perceived own development as improved described respectfully that it was not to the same level as their colleagues, who had taken part from the very beginning. They were surprised and satisfied with own and other participants improvement and felt encouraged and dedicated to the work.

“This participatory approach has broadened our minds...look at him! (pointing at one participant). He is a very good example, a model for personal development...this is the biggest personal development I have ever seen.” Repeat FGD, 5

In the repeat FGDs, participants became more and more aware of the importance of the participatory approach and consequently recognized the meaning of it. Participants discussed the various effects of the intervention, i.e. how it is more important to accomplish long-term sustainability than short-term achievements. This attitude took several years to achieve.

The participants, who placed capacity building of human recourses in favor of hardware recourses, became more confident and satisfied along with the process. They had become able to express ideas in an understandable way both in plenum and to superiors. Leaders and subordinates praised their new way of working and they had received various awards for good work. They also became promoted in their professional and political roles, and had shown a willingness to openly disagree, when they did not believe in certain aspects. They expressed how they felt free and confident in their management role.

"Someday, the hardware provided through the project will be outdated, but the influence related to the ideology of the project will deepen and grow in the future...we will remember this intervention for many years.” Repeat FGD, 4

\subsection{Building of Capacity}

The general opinion was that managers needed higher qualifications. It was perceived that good policies and plans were not enough, managers also needed to have understanding for the implementation of an intervention to accomplish good quality. The common opinion in the repeat FGDs was that the participants should improve the quality of management and learn more. It was emphasized, that managers seriously should consider the importance of taking part in training to become models for others. Combinations of joint training for different levels of managers, performance of repeat FGDs and core group meetings were considered to improve competence. The participatory approach and process development was perceived to result in improved capacity, understanding and for fostering moral.

"This project has fostered a group of competent personnel...several persons have been promoted from 'common staff' to leaders.” Repeat FGD, 5

The influence of the participatory approach, gave rise to reflections on earlier ways of implementing projects and activities. The participants' experience was, that even though they had carried out earlier work according to directives from the 'upper level', they had not achieved very much. They blamed it on their lack of management 
skills and experiences. They considered capacity building as both personal development and improvement of skills.

"We did not have enough management experience earlier...I think capacity building is about two things...first to improve personal ability and understanding...secondly to improve ways of working in order to put ideas into practice.” Repeat FGD, 5

Attitudes to the participatory approach were discussed in all the FGDs. With each FGD views and opinions regarding the intervention and personal development became more and more comprehensive. A pattern that came out was primarily, that the FGDs were something that promoted awareness and understanding of community needs in relation to the community's ability to solve problems. Secondly, the training improved managers' ability to formulate strategies, goals and plans and to carry out activities. Thirdly, the core group meetings improved their experience and promoted transparency, friendship and team spirit. The three components of the intervention were perceived as indispensable for improved management.

"In the FGDs and the core group meetings we learn new things and improve our understanding of how the project meets local peoples' needs as a basis for realistic planning...we also need the theoretical training combined with the practical...this process improves our ability as leaders.” Repeat FGD, 4

Understanding of the ideas of the project was perceived as very important for the success of the intervention and also for the success as managers. Managers were perceived as key players in interventions and lack of understanding of the project from the management side could delay project implementation or even worse, end it. The process orientation and participatory approach provided new ideas, guidelines and methods and participants were motivated to understand more and saw the repeat FGDs and core group meetings as something important to be continued.

When working with the same managers frequently and regularly in all the components, we found that they improved their management skills and understanding of the whole process. However, when we worked with managers, who only participated occasionally (often representing the highest management level), we found that they had not developed management skills and understanding of the implementation process in the same way as those who had participated more frequently and regularly. However, when they noticed the improvement among the subordinated managers, they became interested because they understood that those, who had participated in more components and during a longer time, had developed more.

"We have learned to know the project during the implementation process and we have gained a lot of good knowledge and methods...I hope we can spend half a day in FGDs and core group meeting next year so we can improve understanding and promote the project even more.” Repeat FGD, 5

\subsection{Building up Democratic Thinking through Networking}

In all the focus groups participants emphasized, that the combination of core group meetings and FGDs, where participants from different levels of the system came together in discussions and became familiar with each others' reality promoted networking. The training was perceived to encourage team spirit among different management levels and also to understand the grassroots.

"Through the FGDs, the core group meetings and the training sessions, team spirit has improved...good team spirit is important for the project implementation.” Repeat FGD, 3

The participants, who had taken part in all repeat FGDs, demonstrated advancement and promoted a participatory approach, the multilevel core group meetings were summarized as transparent in sharing information regarding work, planning and recourses.

"In the core group meetings, communication is direct and shared between different management levels, a very transparent way...the upper level managers can learn about the need of the lower level...and meanwhile we can promote friendship...in the FGDs we have an honest communication and we can finally reach a common understanding. It is an easy way of learning about people's opinions and we can understand problems in a more comprehensive way.” Repeat FGD, 5

The intervention model was perceived particularly positive for a sustainable development of minority areas, 
where people are poor, have difficult living conditions and a low educational level.

"This intervention will be helpful for the creation of stability and developments of minority areas, where people are poor, have bad conditions and low educational level.” Repeat FGD, 1

"Even if the upper level has good policies and good plans, it will not help if the project implementer do not have a correct understanding of policies and plans or is sluggish in his/her work.” Repeat FGD, 5

\subsection{Influencing Empowerment through Broad and Long Participation}

The participants' demonstrated different attitudes depending on how long they had taken part in the intervention. It depended on the number of FGDs, training modules and core group meetings they had attended. Some participants, who took part from the beginning (five years) of the project in all training, all repeat FGDs and all core group meetings. They demonstrated more openness to others' opinions; they were willing to share own experiences, were positive to new interventional methods, expressed own attitudes clearly and understood the interventional methodology very well. Other participants, who took part one to three years in all the training, only few repeat FGDs and half of the core group meetings were on their way to realize awareness of the empowerment effect in the methodology. Finally, some had taken part one to three years but in a limited number of training sessions, were new in the repeat FGDs and had only participated in few core group meetings. They illustrated a less open attitude and more traditional thinking.

"We need concrete things to discuss during this meeting. There is a lack of vividness, (said by a person with a higher position and who took part for the first time ever). A responsibility for the facilitator is to encourage the FGDs participants to talk. No one should be missed in a group. Everyone should talk. I suggest that one of the rules can be. Each one should take his turn to talk and express. After some practice, they will become used to the activity, then they will express more openly. This is a kind of training.” Repeat FGD, 5

A comment afterwards from one of the participants, who had participated the longest time in the FGDs was, 'he does not yet understand the method'.

"FGDs are a direct way of communication that includes participants own ideas...some people have problems to understand the discussion partly because of language problems...anyway, the FGDs are encouraging and strengthens communication.” Repeat FGD, 3

Participants, who took part for the first time in the later repeat FGDs and the core group meetings, showed a more traditional way of thinking. It seemed like the repeat FGDs took longer time to be familiar with and value than the core group meetings. Participants were aware of that those who had participated longer time proved encouragingly improved qualifications.

"In the FGDs we can get a broader thinking and improve our ability, this project has benefited our personal development...The project has brought up a group of competent personnel. Several have been promoted to be leaders and that is because of what they have learned from the project...I have been promoted from a common person to a leader...I have the same feeling as my colleague although I have not participated as long as him and have not been personally developed to the same degree.” Repeat FGD, 5

\section{Discussion}

Our interest was to understand how decisions, were made by the managers; how they interpreted their own roles, how they interacted, became involved and more spontaneous, and how they pursued new ideas.

Some key issues emerged out of this study. Firstly, the managers from different levels, participating in the repeat FGDs, joint training and core group meetings, agreed that it helped generate communication, friendship, transparency, trust and improved skills. A second key issue, during the process of implementation, the managers to various degrees became empowered. Fung (2013) [6] has similarly discussed about the link between social capital and community empowerment and social participation for improved power in decision- making. Ultimately, for the stakeholders the repeat FGDs became a practical way for regular monitoring.

\subsection{The Participatory Approach}

We perceived, that improvement of competence, both as managers and as individuals, was a result of the parti- 
cipatory approach and the strengthening of social capital [4]. Putnam refers social capital to connection among individual social networking and the norms of reciprocity and trustworthiness that arise from them. When the managers shared experiences and started to network, they improved understanding of each others' problems and solutions. The sharing of problems and solutions enhanced, when trustworthiness and transparency improved successively. Also, Smith (2007) [27] talks about how interactions enable people to commit themselves to each other, which resulted in a sense of belonging to a social network, which could benefit people. On one hand it might be fascinating to suppose, that the Chinese political system has prepared for building of social capital through the collectivistic behaviour, but it might also be so, that trust needs to become stronger in the Chinese system. In our study we became successively aware of how knowledge, team spirit and shared understanding, through the repeat FGDs, the training and core group meetings, were improved. We believe that this depended on, that the participants started, after a rather long time (some years), to better trust each other. Inspired by Putnam, Smith and others, we defined this as building of social capital. Smith (2007) [27] also argues that organizations might benefit from building of social capital from the aspect of that it can strengthen human capital, lower costs, limit frequent personnel changes and thus keep up the institutional memory and organizational stability.

The improvement of the managers' capacity was from all levels, higher managers learning from lower managers and vice a versa. This we saw as a seed for future democratic management.

The fact that the managers, who participated a long time in the intervention, compared to those who only participated a short time, improved their managing ability more, even though they had a lower position in the organization and a lower educational level. We believe that the intervention including training, repeat FGDs and core group meetings need time. Through the repeat FGDs, the refreshment training and the core group meetings, people were not left alone with their fate, which in itself shaped trust, motivation and encouragement.

\subsection{Managers' Empowerment}

The repeat FGDs and the training modules were by the participants seen as the most important for personal development and improved knowledge, while the core group meetings were perceived very important for transparency.

One objective of the intervention was to improve managers' capacity. Two of the managers, who participated during the whole period (5 years) developed and became assistants in the study. Their capacity was built up and strengthened because of the participation and practice in the project. They developed particular skills as assistant moderators of the FGDs, transcribers and translators. From their experiences and common sense they moved towards recognizing the deeper meaning of asking, searching and learning [28]. The fact, that they improved their management skills in planning, organizing, budgeting, reporting, monitoring and evaluating might be a result of their motivation to seek for understanding. They were in the end of the project assessed to be able to carry out the follow up of the project. Similarly, White (2002) [29] describes in a paper that strengthening research capacity in developing countries is one of the most powerful, cost-effective, and sustainable means of advanced development.

\subsection{Repeat FGDs}

The social interactions in the focus group discussions were observed and attitudes and understanding were changed during the long time (five year) of research. Barbour (1999) [20] argues that the inherent flexibility of the FGD method with appropriate modification can be used as an instrument both to monitor and implement adjustment in organizational change. Furthermore Morgan (1993) [30] state that FGDs have been identified as especially useful for monitoring and evaluation of programmes, as they provide unique access to the range of perspectives and experiences of participants in an interactive process, as they respond to change. FG can simply reflect or monitor change and there is always the potential for the FG process to initiate changes in participants' thinking or understanding, merely through exposure to the interactive process.

We see the component of capacity building of the local managers as a process of a bottom up approach. Growing of the process was a result of the developed capacity of the managers at county and prefecture levels and spread to province and national levels. We understood that it is important to involve managers from all levels if a project should be successful. 


\subsection{Methodological and Interventional Aspects}

Our experience from the repeat FGDs is that all participants engaged actively in the discussions. The successively more open discussions, from the first to the fifth FGDs, were most likely a result of participants becoming familiar with the subject and developed confidence in the group. Our interest was to investigate the managers' role and importance over a long time (five years) in the repeat FGDs. We have obtained more and more information for every new FG discussion performed and therefore fewer citations from FGD 1 appear than from FGD 5.

There were problems with all the required steps of translations (Chinese, English), both in verbal and written forms. It can be assumed, that the translation process impeded understanding, in particular between the principle investigator and the group. To reduce those problems, discussions were held after every FGD and after every transcription to make sure that it was correctly understood. The member checks after every FGD were to confirm the data and thus trustworthiness. FGD 2 has not been possible to transcribe and translate to English because of some changes of the management team in the second year, and is therefore not included in the material. We see it as a methodological strength that the translator, who also was an assistant investigator in the first paper in this series, became increasingly familiar with the FGD method and with time the main moderator in FGDs with Tibetan indigenous women.

The fact that we conducted repeated FGDs with the same group members increased the dynamics and trust with every successive discussion.

\section{Conclusion}

In summary, some key issues emerged out of this study. Firstly, the managers from different levels agreed that the combined methodology of repeat FGDs, training and core group meetings helped generate communication, friendship, transparency, trust and improved skills. A second key issue, during the process of implementation, it was that the managers to various degrees became empowered. Applying repeat FGDs was very useful for the monitoring process of the program. The FGDs provided a range of perspectives and experiences of participants in an interactive process and in response to change. Repeat FGDs emerged initiate change in the participants thinking and understanding.

\section{References}

[1] O’Hare, D. (2004) Can Managers Be Taught to Manage? International Journal of Applied Management Education and Development, 1.

[2] Raczynski, J., Cornell, C.E., Stalker, V., Phillips, M., Dignan, M., Pulley, L. and Levinton, L. (2001) A Multi-Project System Approach to Developing Community Trust and Building Capacity. Journal of Public Health Management Practice, 7, 10-20. http://dx.doi.org/10.1097/00124784-200107020-00004

[3] Fraser, E.D.G., Dougill, A.J., Mabee, W.E., Reed, M. and McAlpine, P. (2006) Bottom up and Top down: Analysis of Participatory Processes for Sustainability Indicators Identification as a Pathway to Community Empowerment and Sustainable Environmental Management. Journal of Environmental Management, 78, 114-127. http://dx.doi.org/10.1016/j.jenvman.2005.04.009

[4] Putnam, R. (1993) The Prosperous Community: Social Capital and Public Life. The American Prospect, 4, 35-42.

[5] Ornelas, J.O., Amell, J., Tran, A.N., Royster, M., Amstrong-Brown, J. and Eng, E. (2009) Understanding African American Men’s Perception of Racism, Male Gender Socialization, and Social Capital through Photovoice. Qualitative Health Research, 19, 552-565. http://dx.doi.org/10.1177/1049732309332104

[6] Fung, K.W. and Hung, S.L. (2013) Strengthening a Community of Poverty in an Affluent Society: Strategies to Build Social Capital in Tin Shui Wai North in Hong Kong. Community Development Journal.

[7] Botes, L. and van Rensburg, D. (2000) Community Participation in Development: Nine Plagues and Twelve Commandments. Community Development Journal, 35, 41-58.

[8] Patel, S. and Mitlin, D. (2002) Sharing Experiences and Changing Lives. Community Development Journal, 37, 125136. http://dx.doi.org/10.1093/cdj/37.2.125

[9] Sheik-Mohamed, A. and Velema, P. (1999) Where Health Care Has No Access: The Nomadic Population of Sub-Saharan Africa. Tropical Medicine and International Health, 4, 695-707.

[10] Ljunggren, A., Huang, Z., Wang, F. and Johansson, E. (2010) Promoting Community Empowerment among Rural Tibetans in Western China Using Focus Group Discussions. Qualitative Health Research, 20, 1183-1191. http://dx.doi.org/10.1177/1049732310370787 
[11] Ljunggren, A., Johansson, E., Wang, C. and Pettersson-Odberg, K. (2009) Endurance of Aloneness among Tibetan Indigenous Women in Western China: Application of Repeat Focus Group Discussions as a Tool for Empowerment and for Data Collection. Health Care for Women International, 30, 824-844. http://dx.doi.org/10.1080/07399330903066210

[12] Chertow, J.M. (2003) Gender, Medicine and Modernity: Childbirth in Tibet Today. Harvard Asia Quarterly, 7, 17.

[13] Wang, R.T. (2000) Critical Health Literacy: A Case Study from China in Schistosomiasis Control. Health Promotion International, 15, 269-274. http://dx.doi.org/10.1093/heapro/15.3.269

[14] Andews, A.B. (2004) Start at the End: Empowerment Evaluation Product Planning. Evaluation and Program Planning, 27, 275-285. http://dx.doi.org/10.1016/j.evalprogplan.2004.04.002

[15] UNDP (2005) Human Development Report. United Nation Development Program. University Press, Oxford.

[16] Singh, S. (2004) Tears from the Land of Snow: Health and Human Rights in Tibet. The Lancet, 364, 1009. http://dx.doi.org/10.1016/S0140-6736(04)17030-X

[17] Norwegian Red Cross Society (2000) Project Proposal in Ganzi Prefecture-Sichuan Province China.

[18] Tibetan Peoples Groups (2003) www.infomekong.com/p_group_Tibetan_1.htm

[19] Rukhsana, G., Nowsher, U. and Hazera, N. (2005) Involving Community in the Process of Local Level Planning: Modalities in the Thana Functional Improvement Pilot Project of Bangladesh. Journal of Health Management, 7, 141150. http://dx.doi.org/10.1177/097206340400700106

[20] Barbour, R. and Kitzinger, J. (1999) Developing Focus Group Research. Sage, London.

[21] Morgan, D. (1988) Focus Groups as Qualitative Research. Sage Publications, London.

[22] Kreuger, R. (1998) Focus Groups: A Practical Guide for Applied Research. Sage Publications, London.

[23] Kunene, P., Xaba, N. and Harrison, A. (2000) Peer Group Discussions as a Method for Research on Adolecents Sexuality: Results from a Pilot Study. International Conferences on AIDS, Abstract No. ThPeD 5664.

[24] Johansson, E., Long, N.H., Diwan, V.K. and Winkvist, A. (2000) Gender and Tuberculosis Control. Perspectives on Health Seeking Behavior among Men and Women in Vietnam. Health Policy, 52, 33-51. http://dx.doi.org/10.1016/S0168-8510(00)00062-2

[25] Bergström, L. (2005) Institutionsutveckling skapas inifrån. Lärdomar från konsulters erfarenheter av stöd till formella och informella regler, Sekretariatet för utvärderingar och intern revision, Swedish International Development Agency. http://www.sida.se/publications

[26] Graneheim, U. and Lundman, B. (2004) Qualitative Content Analysis in Nursing Research: Concept, Procedures and Measures to Achieve Trustworthiness. Nurse Education Today, 24, 105-112. http://dx.doi.org/10.1016/j.nedt.2003.10.001

[27] Smith, M.K. (2007) Social Capital. The Encyclopaedia of Informal Education. www.infed.org/biblio/social_capital.htm

[28] Espallardo, N.L. and Leopando, Z.E. (2000) Evidence Based Family Practice and Quality Improvement in Health Care. The National Centre for Quality Excellence and Research in Family Practice, Manila.

[29] White, F. (2002) Capacity-Building for Health Research in Developing Countries: A Manager's Approach. Revista Panamericana de Salud Pública/Pan American Journal of Public Health, 12, 165-172.

[30] Morgan, D. and Kreuger, R. (1993) The Focus Group Kit. Volumes 1-6, Sage Publications, Inc., Thousand Oaks. 
Scientific Research Publishing (SCIRP) is one of the largest Open Access journal publishers. It is currently publishing more than 200 open access, online, peer-reviewed journals covering a wide range of academic disciplines. SCIRP serves the worldwide academic communities and contributes to the progress and application of science with its publication.

Other selected journals from SCIRP are listed as below. Submit your manuscript to us via either submit@scirp.org or Online Submission Portal.
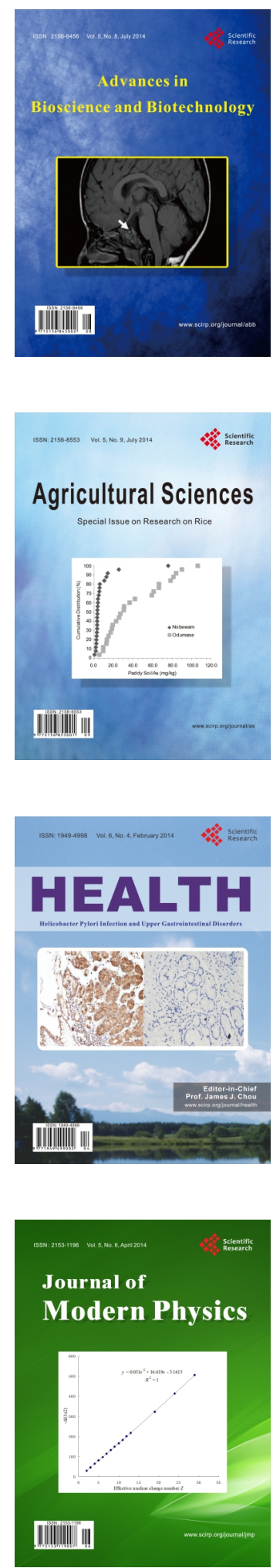
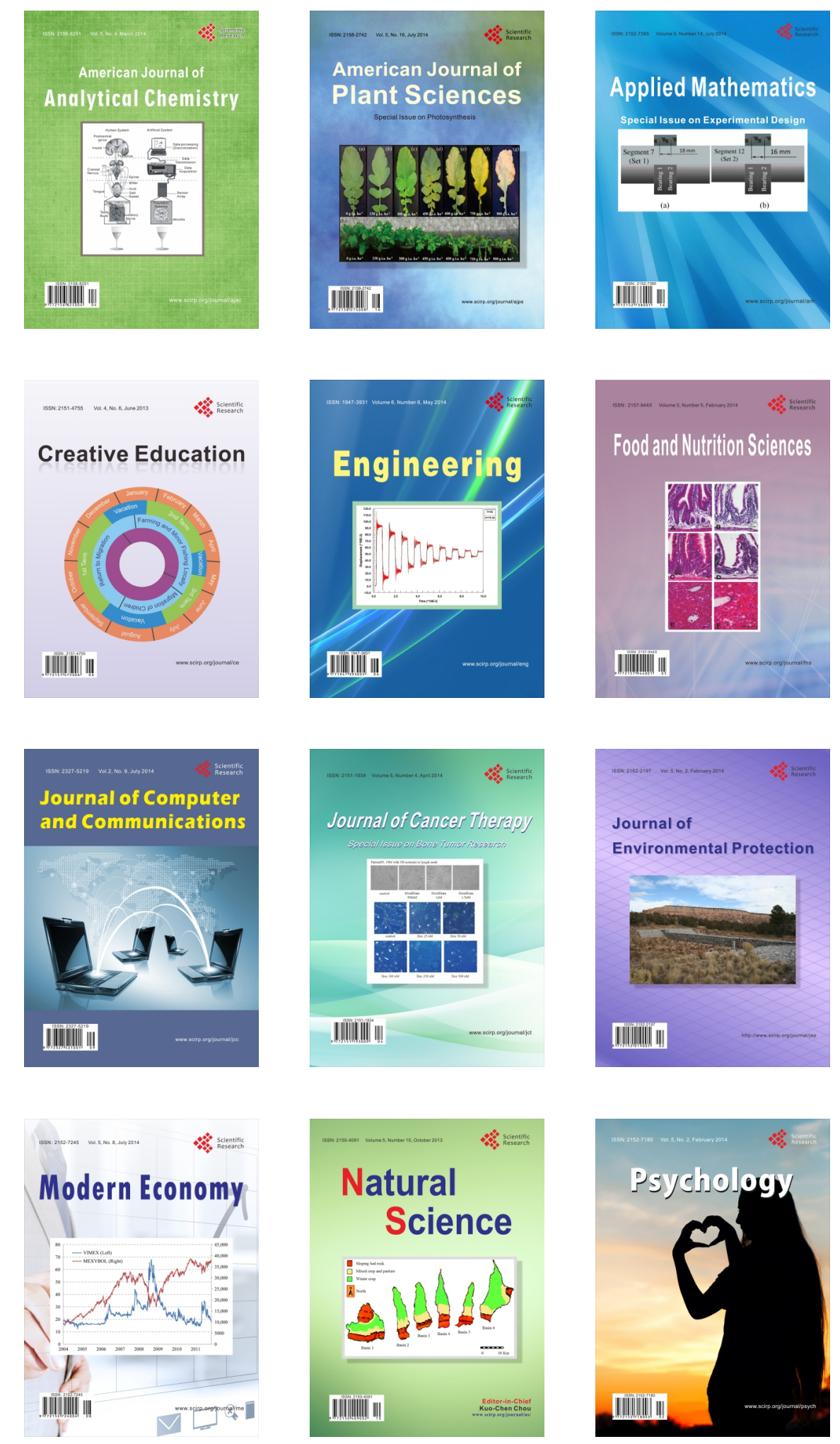